\title{
One-pot green synthesis of some novel n-substituted 5-amino-1,3,4-thiadiazole derivatives
}

\begin{abstract}
In the current study, a green, one-pot, three-component reaction was performed to prepare novel N-substituted 5-amino-1,3,4-thiadiazole derivatives. The thiadiazoles were obtained from the reaction of a ketene S,S-acetal of Meldrum's acid or barbituric acid (as key intermediates), hydrazine, and isothiocyanate. The key advantages of this manner include environmentally safe reactions, high yield, appropriate reaction time, simple reaction conditions, and use of a green reaction solvent. The structure of thiadiazoles was determined based on the spectroscopic data.
\end{abstract}

Keyword: 5-amino-1; 3; 4-thiadiazole; Thiosemicarbazide; Ketene S; S-acetal; Meldrum's acid; Barbituric acid; Deep Eutectic Solvents 